\title{
Retinal stem cells: promising candidates for retina transplantation
}

\author{
Meta W. Djojosubroto • Yvan Arsenijevic
}

Received: 24 May 2007 / Accepted: 29 August 2007 / Published online: 3 October 2007

(C) Springer-Verlag 2007

\begin{abstract}
Stem cell transplantation is widely considered as a promising therapeutic approach for photoreceptor degeneration, one of the major causes of blindness. In this review, we focus on the biology of retinal stem cells (RSCs) and progenitor cells (RPCs) isolated from fetal, postnatal, and adult animals, with emphasis on those from rodents and humans. We discuss the origin of RSCs/RPCs, the markers expressed by these cells and the conditions for the isolation, culture, and differentiation of these cells in vitro or in vivo by induction with exogenous stimulation.
\end{abstract}

Keywords Retina - Stem cells · Progenitor - Differentiation · Transplantation $\cdot$ Radial glia

\section{Introduction}

Retinitis pigmentosa, diabetic retinopathy and age-related macular degeneration (AMD) are the major clinical subtypes of retinal degeneration in which photoreceptors undergo a progressive cell death resulting in the loss of vision. There is currently no effective treatment for either subtype, except in the case of wet AMD (approximately $12 \%$ of all AMD cases) in which early neovascularization can be hindered by anti-angiogenic factors.

Studies with fetal retinal transplants have shown promising results for the treatment of the diseased retina in

Commercial disclosure: none.

M. W. Djojosubroto $\cdot$ Y. Arsenijevic ( $\square)$

Unit of Gene Therapy \& Stem Cell Biology, Jules-Gonin Eye

Hospital, Ophthalmology Department, University of Lausanne,

15 Avenue de France,

1004 Lausanne, Switzerland

e-mail: yvan.arsenijevic@ophtal.vd.ch animal models of retinal degeneration (Silverman and Hughes 1989; Sagdullaev et al. 2003; Arai et al. 2004; Ghosh et al. 1998), although whether the graft participates to maintain vision or simply protects the remaining photoreceptors is not clear. Nonetheless, these encouraging results are currently being followed by a Phase I clinical trial (Radtke et al. 2004). One potential problem arises from the fact that this approach requires a large amount of tissue. Instead of retinal tissue, in-vitro-expanded multipotent stem cells (SCs) could serve as a better source. SCs are defined as cells with the capacity to self-renew and to generate differentiated cells that compose an organ, including the retina (discussed below). Extensive efforts expended on the transplantation of neural and retinal stem cells (RSCs) and progenitor cells (PCs) have shown that this method has promise as a strategy for therapy of diseased retinas (Canola et al. 2007; MacLaren et al. 2006; Young et al. 2000; Klassen et al. 2007; Coles et al. 2004).

Several studies have indicated the possibility of using non-retinal SCs as a donor source. These investigations include the use of cells such as embryonic stem (ES) cells (Schraermeyer et al. 2001; Banin et al. 2006; Lamba et al. 2006), brain-derived precursor cells (Wojciechowski et al. 2004), and bone marrow-derived hematopoietic SCs (Otani et al. 2004; Tomita et al. 2002, 2006). In this review, we will focus only on the SCs and PCs derived from the retina itself.

\section{Niche, proliferation control, and isolation} of RSCs/RPCs

In general, two possible sources of retinal cells show the characteristics of $\mathrm{SCc} / \mathrm{PCs}$ in the mammalian system. One is the adult retinal pigmented ciliary margin (PCM) located 


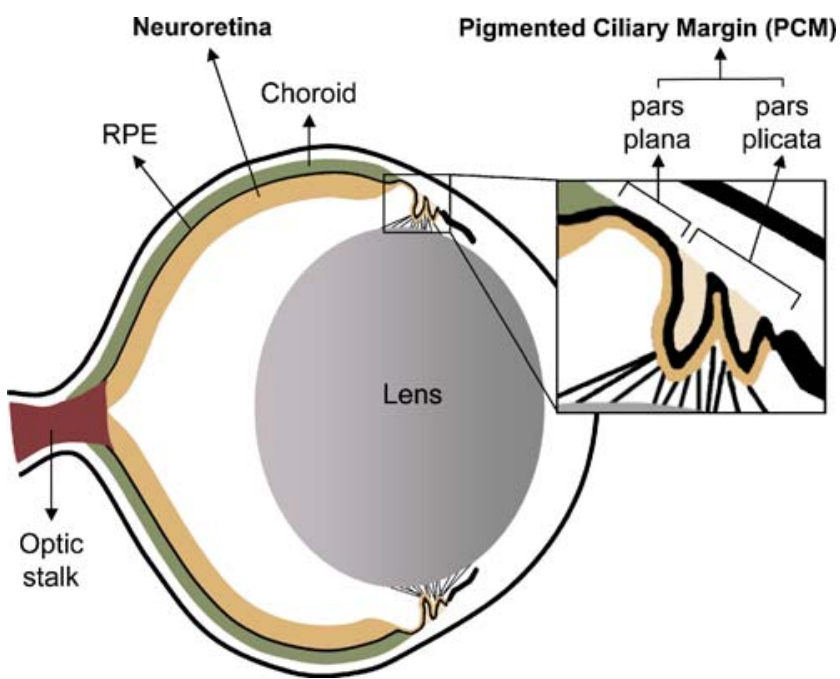

Fig. 1 Representation of a mouse eye after birth. Retinal stem cells, which are located in the neuroretina of the neonatal eye, are found in the pigmented ciliary margin $(P C M)$ of the adult eye ( $R P E$ retinal pigment epithelium)

between the iris and the retina (Perron and Harris 2000; Fig. 1), and the other is the developing neuroretinas of embryos and pups during the first few postnatal days (Fig. 1). In addition, Muller glia have shown a remarkable capability to dedifferentiate into a number of different retinal cell types following an injury, suggesting the existence of another subset of PCs in the adult retina.

\section{RSCs from retinal ciliary margin}

In lower vertebrates, such as fish or frog, the most central part of the retina is formed by RSCs during embryogenesis and thus consists of the oldest cells (Perron et al. 1998; Wetts et al. 1989). Clonal analysis by lineage tracing methods have revealed the multipotentiality of these RSCs during mouse and frog eye development (Turner et al. 1990; Wetts et al. 1989). The peripheral part is formed later, coming from cells of the ciliary margin zone (CMZ) located at the retina extremities (Fernald 1990; Otteson and Hitchcock 2003; Perron and Harris 2000). In chicken, SCs in this region possess the potential to give rise to a large number of progeny, generating retinal neurons, glia, and retinal pigmented epithelial cells, indicating multipotentiality. CMZ RSCs express proteins that are also present in fetal retinal progenitor cells (RPCs), including CHX10 and PAX6 (Fischer and Reh 2000). Following injury, fetal chicken CMZ RSCs can regenerate the retina, starting as early as the first day after retinectomy. Studies have shown that fibroblast growth factor-2 (FGF-2) and Sonic hedgehog (SHH) are interdependent with regard to inducing regeneration from the chicken CMZ after retinectomy (Spence et al. 2007; a list of the genes, and hence factors, involved in eye development and differentiation is given in Table 1).
In the mammalian system, retinogenesis follows the general pattern of central to peripheral growth (for an excellent review of the roles of intrinsic and extrinsic factors controlling retinal expansion and differentiation, see Yang 2004). The last mitosis is executed by PCs near the retinal margin. After retinogenesis is completed, there is no evidence of growth in the retinal PCM of adult mammals (Perron and Harris 2000). Nestin (NES), a neural progenitor marker, and PAX6, a transcription factor controlling retinal growth, are expressed by some cells at the junction of the

Table 1 List of genes that influence eye and retina development and differentiation in vivo and/or in vitro. The first official symbol represents those for mouse (Mus musculus) and rat (Rattus norvegicus), and the second official symbol represent those for chicken (Gallus gallus), human (Homo sapiens), or species other than mouse and rat.

Gene official Gene name
symbol

Cdkn1b/CDKN1B Cyclin-dependent kinase inhibitor 1B (p27, Kip1)

Chx10/CHX10 Ceh-10 homeo domain containing homolog (C. elegans)

Cntf/CNTF Ciliary neurotrophic factor

Crx/CRX Cone-rod homeobox

Egf/EGF Epidermal growth factor (beta-urogastrone)

Fgf-2/FGF-2 Fibroblast growth factor 2 (basic)

Gfap/GFAP Glial fibrillary acidic protein

Hes1/HES1 Hairy and enhancer of split 1 (Drosophila)

Hes5/HES5 Hairy and enhancer of split 5 (Drosophila)

Ifaprc2 Intermediate filament-associated protein RC2

Lif/LIF Leukemia inhibitory factor

Mitf/MITF Microphthalmia-associated transcription factor

Myt1/MYT1 Myelin transcription factor 1

Nes/NES Nestin

Neurod4/

NEUROD4

Notch1/NOTCH1 Notch homolog 1, translocation-associated (Drosophila)

Nrl/NRL Neural retina leucine zipper gene

Pax6/PAX6 Paired box gene 6

Prkca/PRKCA Protein kinase C, alpha

Ptch1/PTCH1

$\mathrm{Ptn} / \mathrm{PTN}$

Patched homolog 1 (Drosophila)

Pleiotrophin/pleiotrophin (heparin binding growth factor 8 , neurite growth-promoting factor 1)

Rax/RAX

Rcvrn/RCVRN

Rho/RHO

Retina and anterior neural fold homeobox

Recoverin

Rom1/ROM1

$\mathrm{Shh} / \mathrm{SHH}$

Tgfa/TGFA

Wnt2b/WNT2B

Rhodopsin

Retinal outer segment membrane protein 1

Sonic hedgehog homolog (Drosophila)

Transforming growth factor alpha

Wingless-type MMTV integration site family, member $2 \mathrm{~B}$

Wnt3a/WNT3A Wingless-type MMTV integration site family, member $3 \mathrm{~A}$ 
neural retina and the ciliary body, suggesting quiescent $\mathrm{RSC} / \mathrm{RPC}$ populations that remain in human and mouse (Mayer et al. 2003; Xu et al. 2007). SHH inactivity may play a role in the non-proliferative state of these cells. SHH exerts most of its actions through PTCH1 (patched homolog 1), a transmembrane protein that, in the absence of SHH, represses the activity of another transmembrane protein SMO (Smoothened). Binding of SHH to PTCH1 inhibits the repression of SMO, leading to the activation of some genes and the de-repression of others through the effects of the Smo and Gli family of transcription factors (for a review, see Riobo and Manning 2007). When one allele of Ptch1 is deleted in mouse eyes, incorporation of BrdU, a synthetic thymidine analog commonly used to mark DNA synthesis, shows that peripheral cells continue to proliferate for a few more days after the normal end of retinogenesis and express the markers of retinal progenitors, such as CHX10, PAX6, and NES (Moshiri and Reh 2004; for a review of the general role of Hedgehog in RSC proliferation, see Agathocleous et al. 2007).

The PCM of mouse eye contains RSCs that have the capacity to proliferate in vitro, with the potential to produce all the cell types of the neural retina, including rod photoreceptors, bipolar neurons, and Muller glia (Tropepe et al. 2000; Ahmad et al. 2000). The RSCs in adult human eyes are also found in the same region. The human eye is estimated to bear a small population of RSCs (approximately 10,000 cells/eye). These cells can be found in human eyes up to at least the seventh decade of life. Within 7 days of culture, single cells isolated from this region generate spheres, some of which are pigmented (Coles et al. 2004). Importantly, only the pigmented spheres show SC characteristics. The similar frequency of SCs between the young postnatal age and over the next 6 decades suggests that the RSC population is maintained from birth to old age. The variability in the sphere-forming ability is highly dependent on the postmortem delay and other factors that are difficult to control when using human organ donation (Coles et al. 2004). Interestingly, the frequency of the sphere-forming cells is greater in the mouse retina at the adult stage compared with embryonic day 14.5 (E14.5; Tropepe et al. 2000), suggesting that the number of SCs increases with developmental time.

RSCs from fetal and postnatal retinas

Mouse RSCs isolated from the neuroretina and RPCs from E17 and postnatal day 1 (PN1) rat and mouse embryos grown as neurospheres express NES (Klassen et al. 2004; Qiu et al. 2005). Moreover, single cells isolated from dissociated retinas of postnatal mouse pups might generate population of cells with self-renewal ability and multipotentiality. These neonatal RSCs isolated from PN1 mouse retinas seem to originate from radial glia as indicated by RC2, Pax6, and Ascl1 ${ }^{\text {Mashl }}$ expression (Angenieux et al. 2006), which are also expressed by radial glia in the brain (Heins et al. 2002). NES and BMI1 are also expressed by these RSCs in vitro (Angenieux et al. 2006). Human fetal RPCs (6th-13th week of gestation) have been isolated from the neural retina. These RPCs show high proliferation in culture medium supplemented with growth factor (epidermal growth factor [EGF] or FGF-2), and the expression of NES in vitro has been observed (Kelley et al. 1995; Yang et al. 2002).

Mitf and Chx10 control the RPC population in vivo. Deletion of one of these genes results in smaller eyes and a significantly lower number of RPCs. Interestingly, this loss of RPCs is paralleled by a higher number of RSCs, indicating a response of mammalian RSC population to signals from RPCs. An RSC appears to undergo an asymmetrical division to produce an $\mathrm{SC}$ and retinal neuronal progenitor, or an $\mathrm{SC}$ and retinal pigment epithelial (RPE) progenitor. Coles et al. (2006) have suggested that the loss of retinal neuron progenitors or RPE progenitors because of Chx10 and Mitf mutations would induce a signal from the RPC populations to the RSCs to undergo more symmetrical divisions, thus resulting in more RSCs.

$\mathrm{CMZ} / \mathrm{PMC}$ SCs are distinct from the PCs in the central part of the developing retina, although both produce all retinal neurons and glia, and both can be identified by the co-expression of PAX6 and CHX10 (Abdouh and Bernier 2006; Fischer and Reh 2000; Belecky-Adams et al. 1997). Chicken CMZ RPCs at E5 produce a larger number of progeny and might proliferate for a longer period when compared with the central RPCs (Kubo et al. 2003). In addition, Das and colleagues (2005) have reported distinct properties of rat adult PMC RSCs and rat fetal RPCs; they have observed that, under the same differentiating conditions, PMC RSCs show a preference to generate larger number of early born neurons (e.g., retinal ganglion cells; RGCs) than fetal RPCs.

\section{Muller glia}

When their environment is disturbed, such as when an injury occurs in the retina, Muller glia from chicken and rat retinas have the potential to dedifferentiate into retinal neurons (e.g., bipolar and rod photoreceptor) under appropriate stimuli (Das et al. 2006a; Fischer et al. 2002; Ooto et al. 2004). The quiescent state of Muller glia is maintained by $C d k n 1 b^{p 27 k i p 1}$, the expression of which inhibits cell cycle entry. $C d k n 1 b^{p 27 k i p 1}$ expression is down-regulated within $24 \mathrm{~h}$ after retinal injury in mouse (Dyer and Cepko 2001). A number of studies suggest roles of Wnt and Notch pathways on the activation of Muller glia, as Notch expression is maintained in these cells (Furukawa 
et al. 2000; Dorsky et al. 1995), and interestingly, Wnt and Notch activities suppress Cdkn1 $b^{p 27 k i p 1}$ (Das et al. 2006a; Castelo-Branco et al. 2003; Sarmento et al. 2005) suggesting that Muller glia are in equlibrium between differentation and proliferation. Furthermore, in response to injury, the administration of WNT2B into PN21 rat eyes leads to a three-fold increase in Muller cell number, whereas inhibition of NOTCH activity by DAPT (a gamma secretase inhibitor) causes a reduction in the number of these cells (Das et al. 2006a). These findings reveal that Muller glia might be recruited to generate endogenously new neurons when induced by the appropriate stimuli.

\section{In vitro propagation of RSCs}

The ability to generate a large number of cells in vitro with defined characteristics is a necessity for well-controlled transplantation. Thus, the attainment of the optimal culture and priming conditions of RSCs remains a major goal. The optimal culture conditions would be those offering the possibility to maintain the self-renewal, multipotentiality, and genetic stability of these cells.

Studies have shown the importance of growth factor supplements to maintain the self-renewal of RSCs in vitro. The mitogenic effect of EGF, FGF-2, and transforming growth factor-alpha (TGFA) in retinal cultures have been studied extensively by several laboratories. These growth factors have been shown to promote the proliferation of RPCs and the survival of rod photoreceptors (Anchan et al. 1991; Hicks and Courtois 1992; Lillien and Cepko 1992). In the absence of growth factors, isolated human RSCs can form spheres. However, the addition of growth factors increases the number of spheres formed significantly (Coles et al. 2004). Current culture methods mostly use EGF and/ or FGF-2 in the growth media at a concentration of 10-20 ng/ $\mathrm{ml}$ (Angenieux et al. 2006; Coles et al. 2004; Klassen et al. 2004; Merhi-Soussi et al. 2006; Tropepe et al. 2000).

Postnatal mouse RSCs/RPCs have been shown to propagate as non-adherent spheres or as a monolayer culture in the presence of growth factor(s) (Klassen et al. 2004; Tropepe et al. 2000; Angenieux et al. 2006). RPCs have been cultured in the presence of $20 \mathrm{ng} / \mathrm{ml} \mathrm{EGF}$ as nonadherent spheres and are capable of expansion through more than 60 passages (Klassen et al. 2004). These cells seem to be more related to neuroepithelial cells, as previously described for brain neural SCs grown as spheres (Gregg and Weiss 2003). Results from our group have shown that mouse RSCs isolated from the radial glia population in PN1 mouse retinas can be cultured as a monolayer. Single cells of neonatal RSCs first grow as small colonies of radial glial cells that give rise to a monolayer within 1 month and can be maintained in culture medium supplemented with FGF-2 and EGF. All cells $(100 \%)$ express the radial glia marker RC2 and the Pax6 and $\mathrm{Ascl1}{ }^{\text {Mash } 1}$ genes, which are expressed in the radial glia of other areas of the central nervous system (Gotz et al. 1998; Conti et al. 2005). Moreover, the cells display the typical morphology of radial glia: bipolar, elongated, small ramifications at the extremities (see the review of radial glia and neural SCs by Malatesta et al. in this edition of Cell and Tissue Research). In our hands, these cells are able to proliferate to at least passage $34\left(>10^{46}\right.$ cells). These cells remain homogeneous in an undifferentiated state, even after extensive passaging, as shown by the expression of the progenitor markers NES, BMI1, Ascl1 ${ }^{\text {Mashl }}$, and Pax6 and by the lack of differentiated cell markers, such as glial fibrillary acidic protein (GFAP) or beta-tubulin 3 (Angenieux et al. 2006). These cells have a vigorous capacity to maintain their potential to generate neurons, even after extensive passaging (Merhi-Soussi et al. 2006). Importantly, neural SCs isolated from brain radial glia have similar characteristics of expansion and robust differentiation (Conti et al. 2005).

Adult rat PMC RSCs exhibit GFAP expression, which in most cells co-localizes with BrdU, indicating that GFAP is expressed by these cells in a proliferating condition. GFAP also co-localizes with NES and NOTCH1, further confirming the neural progenitor nature of these cells in vitro (Das et al. 2006b). Human RSCs have been successfully cultured as spheres to at least passage 13. However, the number of new spheres generated drops significantly after passage 3 , and SCs have been maintained in culture, but not expanded. A monolayer culture in EGF + fetal bovine serum (FBS) or in FGF-2 + FBS from a single sphere originating from a single cell can generate $10^{11}$ cells in about 2 months (approximately 37 population-doublings) and then senesces. During proliferation, these cells express NES (Coles et al. 2004).

The lack of serum dependency during cell expansion is favorable, as animal-derived serum might contain unidentified factors. Moreover, animal proteins are immunogenic and might contain microorganisms, making it less safe for clinical application. Serum-free media have been successfully used to culture fetal and postnatal RSCs/RPCs in an undifferentiated state (Akagi et al. 2003; Angenieux et al. 2006; Qiu et al. 2004; Klassen et al. 2004). Thus far, human PCM RSCs need the presence of $10 \%$ FBS during proliferation. Interestingly, when FBS is removed from monolayer culture, a few cells from the monolayer are able to proliferate as retinal spheres, indicating the presence of RSCs (Coles et al. 2004). Porcine RPCs expanded in vitro require a short exposure to FBS to adhere to the substrate. After withdrawal of FBS, these cells remain in the monolayer condition (Klassen et al. 2007). Recent studies have shown that the addition of $20 \%$ porcine aqueous 
humor to culture medium containing EGF $(20 \mathrm{ng} / \mathrm{ml})$ enhances the proliferation of rat RPCs by as much as $317 \%$ compared with controls, and the spheres are also larger when aqueous humor is supplemented. This enhanced proliferation is partially attributable to the presence of ascorbic acid in the humor (Yang et al. 2006). The different composition between primate aqueous humor and serum has been previously reported (Gaasterland et al. 1979). The addition of ascorbic acid may help to propagate human RSCs that show limited expansion ability.

Maintenance of proliferation and undifferentiated state of RSCs/RPCs

NOTCH activity is necessary in RPCs to maintain their undifferentiated states (Jadhav et al. 2006; Silva et al. 2003; Nelson et al. 2006; Yaron et al. 2006). Primary spheres isolated from retinas with a constitutive overexpression of Notch 1 show an extended proliferation with $9 \%-10 \%$ of the cells forming secondary and tertiary spheres. Sphere formation has been observed even at P60. Overexpression of Notch1 does not seem to affect proliferation rates (Jadhav et al. 2006). Canonical NOTCH signaling in mammals requires presenilin/gamma-secretase-mediated release of the intercellular domain of the notch homologs (Saxena et al. 2001). Inhibition of NOTCH by DAPT, a gamma-secretase inhibitor, causes a reduction of the NOTCH downstream targets HES5 and HES1 and in an increase of NOTCH-antagonist MYT1, all of which are known to promote neural differentiation (Nelson et al. 2007). These results show that NOTCH is involved in the control of retinal stemness.

Pax6, a gene encoding a transcription factor required to maintain the multipotentiality of RPCs (Marquardt et al. 2001), is found to be expressed by cells in the PCM. Interestingly, the cells on the inner side of the layer show weaker PAX6 staining than those on the outer side of the layer. The difference in PAX6 staining intensity might indicate that the cells on the outer side are SCs, and that those on the inner side are progenitors. The expression level of Pax6 clearly dictates the self-renewal ability of RSCs, since deletion of one allele results in a lower number of secondary spheres and smaller eyes (Xu et al. 2007).

Neonatal RSCs/RPCs, both in monolayer and in spheres, show positive immunostaining of NES, a characteristic of PCs (Lendahl et al. 1990). Neonatal RSCs also display BMI1 (Angenieux et al. 2006), a protein required for neural stem proliferation (Molofsky et al. 2003; Zencak et al. 2005). In addition, mouse RPCs from dissociated neonatal retinas manifest SOX2 (Klassen et al. 2004), which is needed to maintain the proliferative state of RPCs in developing retina and, in a dose-dependent manner, plays a key role in the correct differentiation and placement of retinal cells, mostly by its regulation on the Notch signaling pathway. Its expression has also been detected in Muller glia (Taranova et al. 2006).

In chicken retina, the Wnt pathway has been demonstrated to promote the proliferation of PCs. Overexpression of $W n t 2 b$ in ovo inhibits neural differentiation and induces the expression of PC markers. The data indicate that WNT2B maintains the undifferentiated state of the PCs in the $\mathrm{CMZ}$ and thus serves as a putative $\mathrm{SC}$ factor in the retina (Kubo et al. 2003). A recent study has shown that WNT3A administration can increase the proliferation of Muller glia in rat retinal explants following an injury and can promote the dedifferentiation of these cells into retinal progenitor-like cells that express markers such as PAX6 and CHX10 (Osakada et al. 2007).

Accumulating evidence suggests that RSCs/RPCs are relatively easy to expand and can be maintained through extensive passages without differentiation or loss of their multipotentiality. However, several concerns must be raised. First, no standard culture conditions exist, as each laboratory works with its own subset of cells, which require different growth media and factors and specific culture conditions. This makes it difficult to compare results or to reproduce results obtained by other laboratories. Nonetheless, the finding that several different locations bear SCs/ PCs or precursor cells in the retina might be helpful in discovering the best type of cells that are mobile and can regenerate the retina, thus improving therapeutic efficacy in patients. Second, extensive culturing might increase the genomic instability of the cells, making them unsafe for transplantation. Tumor formation has been observed after the transplantation of ES-cell-derived neural precursor cells into the mouse subretinal space (Arnhold et al. 2004); this might have been promoted by the unlimited self-renewal of ES cells, although a number of studies have reported the spontaneous transformation of adult SCs in vitro (Rubio et al. 2005; Shiras et al. 2007). The optimization of culture conditions involving the lowering of cellular stress levels, e.g., exposure to chemicals, oxidation, toxins, and thus the enhancement of genomic stability in culture might ensure a safer batch of cells for transplantation.

\section{Differentiation of retinal cells in vitro}

Retinal cells are generated in a stereotyped sequence (Cepko et al. 1996; Young 1985; Rapaport et al. 2004). The vertebrate neural retina comprises seven neural cell types, which are derived from one population of multipotent progenitors (Wetts and Fraser 1988; Turner et al. 1990). Upon exiting the cell cycle, retinal progenitors differentiate into six defined neuronal cell types and one glial type in a precise temporal and spatial manner (Cepko 
et al. 1996). RGCs are generated first, followed by overlapping phases of development for horizontal cells, cones, amacrine cells, rods, and bipolar cells. In vitro, retinal progenitors at different stages differ in their competence to produce distinct cell types, suggesting that the determination of cell fate is regulated by both cellintrinsic and cell-extrinsic factors (Reh and Kljavin 1989; Watanabe and Raff 1990; Belliveau and Cepko 1999; Rapaport et al. 2001). However, the environment has been reported to change the possible final fate of late RPCs isolated from E18 rat retinas, as these cells can develop into RGCs that are normally produced early during development; this finding suggests that the fate of these late RPCs is reversible and might be inducible by extrinsic factor(s) (James et al. 2003; for more on intrinsic and extrinsic signals that determine retinal lineages, see Cayouette et al. 2006).

Our results from clonal analysis have shown that mouse neonatal RSCs harbor the potential to differentiate toward a glial or neural fate (Angenieux et al. 2006). Interestingly, we have observed a number of neurons expressing RGC markers confirming that late RSCs can generate early neurons. A more extensive analysis with the neonatal RSCs derived from the radial glia population has demonstrated their potential to differentiate into the photoreceptor lineage (Merhi-Soussi et al. 2006). However, whether a single neonatal RSC is able to generate all retinal cell types in vitro remains to be determined.

Differentiation to photoreceptors in vitro is densitydependent (Watanabe and Raff 1990; Altshuler and Cepko 1992), suggesting that environmental factors control fate acquisition. Induction of retinal neurons, including photoreceptors, is mostly performed by the administration of retinoids. Retinoids and their receptors are expressed during the stages of retinogenesis when decisions regarding cell fate appear to be made (Kelley et al. 1999). Retinoic acid regulates the expression of $\mathrm{Nrl}$ (neural retina leucine zipper), a basic motif-leucine zipper (bZIP) transcription factor, which activates the expression of rod-specific genes (Khanna et al. 2006). In vitro, the addition of retinoic acid to dissociated retina culture from fetal and neonatal rats causes a dose-dependent specific increase in the number of photoreceptors. In the same cultures, retinoic acid also leads to a decrease of amacrine cell development. The total number of cells induced to differentiate into photoreceptors by retinoic acid treatment is much lower in E15 cultures than in cultures established on E18 or P0. Thus, retinoic acid might only have an effect on those PCs that have become restricted to differentiate as later retinal phenotypes, such as amacrine cells or rod photoreceptors (Kelley et al. 1994). With mouse neonatal RSCs derived from the radial glia, a high yield of photoreceptors $(25 \%-35 \%$ of total cell number) has been achieved by applying a priming step involving FGF-2 and heparan sulfate for 5 days continued by the addition of a B27 supplement containing retinoic acid. FGF-2 priming induces neuronal commitment and the B27 supplement directs subpopulations of these neurons toward a photoreceptor, amacrine, or Muller cell fate. Direct plating of mitogen-expanded RSCs onto laminin-coated cover-slips and incubation with B27, without FGF-2 priming, generates a large number of glial cells and few neurons, showing that the FGF-2 priming procedure is necessary to generate numerous neurons (Merhi-Soussi et al. 2006; Wu et al. 2002). Administration of all-trans retinoic acid to human fetal RPCs leads to a higher total cell number and an increase of approximately four-fold in recoverin-positive cells compared with controls (Kelley et al. 1995). Upon differentiation, human fetal RPCs express the early neuronal marker class III betatubulin, the more mature neuronal markers NSE, and glial marker GFAP, indicating their potential to develop into neurons and glia in vitro (Yang et al. 2002).

Several growth factors and chemical agents have been shown to have effects on rod photoreceptor formation. FGF-2 at $10 \mathrm{ng} / \mathrm{ml}$ has been demonstrated to increase the number of opsin-positive cells to as many as six-fold more than in controls (Hicks and Courtois 1992). Taurine (amino-ethyl-sulphonic acid) has been found to enhance the formation of rod photoreceptors. Rod development in retinal explants is competitively inhibited by treatment with a taurine antagonist. However, the effect of taurine is celldensity-dependent, indicating that taurine does not act alone in promoting rod photoreceptor formation (Altshuler et al. 1993). Moreover, S-laminin, an extracellular matrix component present in the neural retina, has an expression that parallels the differentiation of rod photoreceptors. S-laminin interacts with photoreceptors in vitro, and antibodies to s-laminin profoundly reduce the appearance of cells that express rhodopsin (Hunter et al. 1992).

Concerning cytokines, administration of ciliary neutrophic factor (CNTF) appears to have contradictory effects in different species. In dissociated chicken retina, the addition of CNTF increases the number of rod photoreceptors approximately four-fold compared with the control (Fuhrmann et al. 1995). This effect of CNTF is restricted to a transient phase of CNTF receptor- $\alpha$ expression, between the final mitosis and differentiation. CNTF-differentiated rods depend on additional protective factors for survival. In the absence of antioxidant agents such as retinol, CNTF-stimulated differentiation is followed by a phase of photoreceptor-specific apoptotic cell death (Fuhrmann et al. 1998). Contrary to its effects on chicken retinas, in mouse and rat, both CNTF and leukemia inhibitory factor (LIF) strongly inhibit rod photoreceptor differentiation (Ezzeddine et al. 1997; Kirsch et al. 1998; Neophytou et al. 1997; Schulz-Key et al. 2002) and redirect their phenotype toward the bipolar cell lineage and glia (Roger et al. 2006; Zahir et al. 2005). Differentiation into 
bipolar and glia is marked by the down-regulation of Hes 1 , Nestin, and Pax6 and an increase in the expression of protein kinase C (PKC) alfa and GFAP (Zahir et al. 2005). CNTF and LIF upregulate Pleiotrophin, the overexpression of which prevents photoreceptor differentiation and induces bipolar cell formation (Roger et al. 2006). In vivo, the CNTF/LIF pathway regulates the expression of neuronal and endothelial nitric oxide synthase genes, thus modulating the cell death of postmitotic rod precursor cells (Elliott et al. 2006).

In addition to its role in RPC maintenance, studies have indicated that Notch regulates the neuronal versus glial fate choice (Jadhav et al. 2006; Nelson et al. 2006). In postnatal retinas, the generation of Muller glia has been found to be promoted by RAX, HES1, and NOTCH1 (Furukawa et al. 2000). Moreover, sorbitol, in the absence of glucose, has been shown to direct the late RPCs to a Muller glial fate (Zahir et al. 2006).

Using a retroviral expression system on rat retinal explants, Ooto and colleagues (2004) have observed that, in activated Muller glia, co-misexpression of NeuroD and Pax6 promotes amacrine cell differentiation $(\sim 25 \%$ of infected cells), co-misexpression of Math3 and Pax6 promotes amacrine $(\sim 19 \%)$ and horizontal cell genesis $(\sim 3 \%)$, whereas co-misexpression of $\mathrm{Crx}$ and NeuroD increases the number of rhodopsin-positive cells $(\sim 18 \%$ of infected cells). Furthermore, rat and macaque Muller glia can be redirected toward a neuronal lineage in vitro following treatment with platelet-derived growth factor and valproic acid. Interestingly, expression of the immature neuronal marker beta-tubulin is only observed in Muller glia cultured as aggregates, but not in those cultured as a monolayer (Kubota et al. 2006). In vivo, the injection of insulin and FGF-2 leads a fraction of Muller glia in chicken retina to differentiate into neurons (Fischer et al. 2002). Despite the increasing number of studies, the dedifferentiation conditions required for Muller glia to change into retinal neurons in vitro remains to be further explored.

\section{Transplantation of RSCs}

To date, the aim of transplantation in the retina is the survival, migration, engraftment, and differentiation of the transplanted cells in the right place under unidentified environmental stimuli, thereby revealing the potential of the progenitor/SC studied. Such an approach can then be applied to replace the dead or diseased host cells with functional donor cells. The type and degree of retinal degeneration probably influence the type of transplantation that is the most effective. Fetal retinal sheet transplant engrafts by forming an extra layer to the host retina (Ghosh et al. 1998; Sagdullaev et al. 2003), making it an attractive candidate for the therapy of late-stage degenerated retinas.
In retinas still undergoing degeneration, cell transplantation might offer better integration into the host retina (Canola et al. 2007; MacLaren et al. 2006; Guo et al. 2003; Nishida et al. 2000; Young et al. 2000). Moreover, the transplanted cells (e.g., retinal neurons) should be able to make the proper connections to the brain in order to become functional. In addition to these considerations, the ability to generate an adequate number of cells that can be directed into the correct type of cell for transplantation remains a major problem.

In comparison with adult SCs derived from organs other than the eye, such as marrow stromal cells, the transplantation of RPC or retinal precursor cells has been reported to give a better result to date (Tomita et al. 2006). Transplantation of fresh dissociated retinal cells from newborn mouse retinas (PN1-7) into littermate wild-type mice has shown that large numbers of cells migrate and engraft into the photoreceptor layer. These engrafted cells have excellent cone and rod photoreceptor morphology and express markers of photoreceptor such as rhodopsin. Interestingly, the best result is obtained with cells at PN3-5, which corresponds to 2-3 days after the peak of rod photoreceptor formation in mouse eyes. Cell cycle analysis has revealed that these precursors are postmitotic. This might indicate a time-specific advantage in transplantation for photoreceptor generation and integration. Calcium imaging and electrophysiology of the transplanted cells have demonstrated their functionality. In addition, the cells engrafted in retinas of mouse models of inherited retinal degeneration have been reported to be functional, since a better pupil light-reflex response is obtained from the treated mouse eyes compared with the control eyes (MacLaren et al. 2006). Using in vitro propagated neonatal RSCs, our group has observed that, after transplantation, these cells have the tendency to differentiate into RGCs, and only a few exhibit other retinal neuron phenotypes or express specific markers of the retinal neuron (e.g., photoreceptors; Canola et al. 2007). Furthermore, transplantation of the same subset of cells after in vitro induction to the photoreceptor fate has revealed that these cells do not survive the host environment, even though the cells can integrate within the retina and express photoreceptor markers. Surviving grafted cells express glial marker (GFAP) and become incorporated within the ganglion cell layer and the inner plexiform layer (Canola and Arsenijevic 2007). Interestingly, the transplantation of expanded RPCs into mice with degenerating retinas has resulted in the preservation of some visual functions, despite the small number of engrafted cells, suggesting a neuroprotective effect conferred by the transplanted cells (Klassen et al. 2004).

Qiu and colleagues (2005) have transplanted RPCs isolated from E17 rat retinas into the subretinal space of PN17 rat models of retina degeneration and have observed 
the organization of a sheet composed of several layers of cells at the transplantation area. Most of these cells $(\sim 80 \%)$ express photoreceptor markers. The observation that no cells are integrated in the retina suggests that the stage of cells transplanted is not fully appropriate, or/and that environment is not favorable for integration (Qiu et al. 2005). With respect to Muller cells, rat Muller glia transplanted into the subretinal space exhibit the expression of a photoreceptor-specific opsin marker (RET-P1; Kubota et al. 2006), showing the possibility for inducing photoreceptor genes in Muller cells. In large mammals, the transplantation of porcine RPCs into the subretinal space of pig eyes has demonstrated the integration of grafted cells, which survive for a period of at least 5 weeks, with most cells expressing photoreceptor markers and a subset of cells expressing glial markers (Klassen et al. 2007). Interestingly, with the same culture and transplantation procedures, more encouraging results have been obtained in pig experiments than in mouse. The delivery of cells into the pig retina might be less damaging to the retina, as it is facilitated by the eye size. This observation clearly engenders more enthusiasm for human applications.

Human PCM RSCs transplanted into the eyes of chicken embryos and of immunodeficient NOD/SCID mice (severe combined immunodeficiency mutation on a non-obese diabetic background) at PN1 integrate into the various neuronal layers at the appropriate developmental time (i.e., ganglion cells during early development and photoreceptors later). In addition, the integrated cells display photoreceptor morphology and expressed ROM1, a rod photoreceptor protein (Coles et al. 2004).

The use of a biodegradable polymer such as the combination of poly(lactic-co-glycocylic acid) and poly (L-lactic acid) shows a promising improvement with regard to enhancing the success rate of transplantation. Scaffolds are fully covered by RPCs in 3 days. The attachment of RPCs to the polymer scaffold is associated with the downregulation of immature markers and the up-regulation of markers of differentiation. This suggests that the scaffold may promote the differentiation of RPCs (Lavik et al. 2005). Furthermore, RPCs grafted on these polymers result in a near 10-fold increase in the number of surviving transplanted cells after 4 weeks. These cells also express mature retinal cell markers such as GFAP, protein kinase C-alpha, recoverin, and rhodopsin (Tomita et al. 2005).

Despite extensive work on various species and the promising results obtained, the transplantation of RSCs/ RPCs remains a challenge. One problem is the choosing of the "right cells", with the options being, for example, mitotic or postmitotic, primed or not primed, freshly isolated or cultured, and dissociated cells or sheet of cells. In addition, the possibility of using non-retinal $\mathrm{SCs} / \mathrm{PCs}$ as other potential cell sources to treat retinal diseases (Banin et al. 2006; Lamba et al. 2006; Otani et al. 2004; Schraermeyer et al. 2001; Tomita et al. 2002, 2006; Wojciechowski et al. 2004) might also benefit this field of research. Another problem concerns the "right methods", such as where and when to inject. So far the best results of transplantation have been achieved when the injection is carried out at an early age or when the degeneration of the retina in animal models with the disease is at an early stage. For clinical applications, the determination of the specific therapeutic windows for transplantation would be advantageous, as it might provide a better result for patients with different degrees of retinal degeneration.

\section{Concluding remarks}

Studies have shown that adult RSCs/RPCs from retinal CPM or fetal/neonatal retinas have the ability to self-renew and differentiate into different retinal cell lineages both in vitro and in vivo. However, whether the integrated transplanted cells by themselves can integrate within the retina network, become fully functional, and establish new connections remains unclear. Several experiments have hinted that pinpointing the best "age" of RSCs/RPCs and the best timewindow for transplantation continues to be a major challenge, as revealed by a study of the transplantation of primary postmitotic newborn retinal cells (MacLaren et al. 2006). Furthermore, interdisciplinary studies such as a combination of regular tissue culture with tissue engineering might further enhance the proliferation, differentiation, survival, and engraftment of transplanted RSCs/RPCs.

Acknowledgment The authors thank Dusan Zencak, Pratyaksha Wirapati, and Dana Wanner for critical discussion and proofreading of the manuscript.

\section{References}

Abdouh M, Bernier G (2006) In vivo reactivation of a quiescent cell population located in the ocular ciliary body of adult mammals. Exp Eye Res 83:153-164

Agathocleous M, Locker M, Harris WA, Perron M (2007) A general role of hedgehog in the regulation of proliferation. Cell Cycle 6:156-159

Ahmad I, Tang L, Pham H (2000) Identification of neural progenitors in the adult mammalian eye. Biochem Biophys Res Commun 270:517-521

Akagi T, Haruta M, Akita J, Nishida A, Honda Y, Takahashi M (2003) Different characteristics of rat retinal progenitor cells from different culture periods. Neurosci Lett 341:213-216

Altshuler D, Cepko C (1992) A temporally regulated, diffusible activity is required for rod photoreceptor development in vitro. Development 114:947-957

Altshuler D, Lo Turco JJ, Rush J, Cepko C (1993) Taurine promotes the differentiation of a vertebrate retinal cell type in vitro. Development 119:1317-1328 
Anchan RM, Reh TA, Angello J, Balliet A, Walker M (1991) EGF and TGF-alpha stimulate retinal neuroepithelial cell proliferation in vitro. Neuron 6:923-936

Angenieux B, Schorderet DF, Arsenijevic Y (2006) Epidermal growth factor is a neuronal differentiation factor for retinal stem cells in vitro. Stem Cells 24:696-706

Arai S, Thomas BB, Seiler MJ, Aramant RB, Qiu G, Mui C, Juan E de, Sadda SR (2004) Restoration of visual responses following transplantation of intact retinal sheets in rd mice. Exp Eye Res 79:331-341

Arnhold S, Klein H, Semkova I, Addicks K, Schraermeyer U (2004) Neurally selected embryonic stem cells induce tumor formation after long-term survival following engraftment into the subretinal space. Invest Ophthalmol Vis Sci 45:4251-4255

Banin E, Obolensky A, Idelson M, Hemo I, Reinhardtz E, Pikarsky E, Ben Hur T, Reubinoff B (2006) Retinal incorporation and differentiation of neural precursors derived from human embryonic stem cells. Stem Cells 24:246-257

Belecky-Adams T, Tomarev S, Li HS, Ploder L, McInnes RR, Sundin O, Adler R (1997) Pax-6, Prox 1, and Chx10 homeobox gene expression correlates with phenotypic fate of retinal precursor cells. Invest Ophthalmol Vis Sci 38:1293-1303

Belliveau MJ, Cepko CL (1999) Extrinsic and intrinsic factors control the genesis of amacrine and cone cells in the rat retina. Development 126:555-566

Canola K, Arsenijevic Y (2007) Generation of cells committed towards the photoreceptor fate for retinal transplantation. Neuroreport 18:851-855

Canola K, Angenieux B, Tekaya M, Quiambao A, Naash MI, Munier FL, Schorderet DF, Arsenijevic Y (2007) Retinal stem cells transplanted into models of late stages of retinitis pigmentosa preferentially adopt a glial or a retinal ganglion cell fate. Invest Ophthalmol Vis Sci 48:446-454

Castelo-Branco G, Wagner J, Rodriguez FJ, Kele J, Sousa K, Rawal N, Pasolli HA, Fuchs E, Kitajewski J, Arenas E (2003) Differential regulation of midbrain dopaminergic neuron development by Wnt-1, Wnt-3a, and Wnt-5a. Proc Natl Acad Sci USA 100:12747-12752

Cayouette M, Poggi L, Harris WA (2006) Lineage in the vertebrate retina. Trends Neurosci 29:563-570

Cepko CL, Austin CP, Yang X, Alexiades M, Ezzeddine D (1996) Cell fate determination in the vertebrate retina. Proc Natl Acad Sci USA 93:589-595

Coles BL, Angenieux B, Inoue T, Rio-Tsonis K, Spence JR, McInnes RR, Arsenijevic Y, Kooy D van der (2004) Facile isolation and the characterization of human retinal stem cells. Proc Natl Acad Sci USA 101:15772-15777

Coles BL, Horsford DJ, McInnes RR, Kooy D van der (2006) Loss of retinal progenitor cells leads to an increase in the retinal stem cell population in vivo. Eur J Neurosci 23:75-82

Conti L, Pollard SM, Gorba T, Reitano E, Toselli M, Biella G, Sun Y, Sanzone S, Ying QL, Cattaneo E, Smith A (2005) Nicheindependent symmetrical self-renewal of a mammalian tissue stem cell. PLoS Biol 3:e283

Das AV, James J, Rahnenfuhrer J, Thoreson WB, Bhattacharya S, Zhao X, Ahmad I (2005) Retinal properties and potential of the adult mammalian ciliary epithelium stem cells. Vision Res 45:1653-1666

Das AV, Mallya KB, Zhao X, Ahmad F, Bhattacharya S, Thoreson WB, Hegde GV, Ahmad I (2006a) Neural stem cell properties of Muller glia in the mammalian retina: regulation by Notch and Wnt signaling. Dev Biol 299:283-302

Das AV, Zhao X, James J, Kim M, Cowan KH, Ahmad I (2006b) Neural stem cells in the adult ciliary epithelium express GFAP and are regulated by Wnt signaling. Biochem Biophys Res Commun 339:708-716
Dorsky RI, Rapaport DH, Harris WA (1995) Xotch inhibits cell differentiation in the Xenopus retina. Neuron 14:487-496

Dyer MA, Cepko CL (2001) p27Kip1 and p57Kip2 regulate proliferation in distinct retinal progenitor cell populations. J Neurosci 21:4259-4271

Elliott J, Cayouette M, Gravel C (2006) The CNTF/LIF signaling pathway regulates developmental programmed cell death and differentiation of rod precursor cells in the mouse retina in vivo. Dev Biol 300:583-598

Ezzeddine ZD, Yang X, DeChiara T, Yancopoulos G, Cepko CL (1997) Postmitotic cells fated to become rod photoreceptors can be respecified by CNTF treatment of the retina. Development 124:1055-1067

Fernald RD (1990) Teleost vision: seeing while growing. J Exp Zool Suppl 5:167-180

Fischer AJ, Reh TA (2000) Identification of a proliferating marginal zone of retinal progenitors in postnatal chickens. Dev Biol 220:197-210

Fischer AJ, Reh TA (2003) Growth factors induce neurogenesis in the ciliary body. Dev Biol 259:225-240

Fischer AJ, McGuire CR, Dierks BD, Reh TA (2002) Insulin and fibroblast growth factor 2 activate a neurogenic program in Muller glia of the chicken retina. J Neurosci 22:9387-9398

Fuhrmann S, Kirsch M, Hofmann HD (1995) Ciliary neurotrophic factor promotes chick photoreceptor development in vitro. Development 121:2695-2706

Fuhrmann S, Heller S, Rohrer H, Hofmann HD (1998) A transient role for ciliary neurotrophic factor in chick photoreceptor development. J Neurobiol 37:672-683

Furukawa T, Mukherjee S, Bao ZZ, Morrow EM, Cepko CL (2000) rax, Hes1, and notch1 promote the formation of Muller glia by postnatal retinal progenitor cells. Neuron 26:383-394

Gaasterland DE, Pederson JE, MacLellan HM, Reddy VN (1979) Rhesus monkey aqueous humor composition and a primate ocular perfusate. Invest Ophthalmol Vis Sci 18:1139-1150

Ghosh F, Arner K, Ehinger B (1998) Transplant of full-thickness embryonic rabbit retina using pars plana vitrectomy. Retina $18: 136-142$

Gotz M, Stoykova A, Gruss P (1998) Pax6 controls radial glia differentiation in the cerebral cortex. Neuron 21:1031-1044

Gregg C, Weiss S (2003) Generation of functional radial glial cells by embryonic and adult forebrain neural stem cells. J Neurosci 23:11587-11601

Guo Y, Saloupis P, Shaw SJ, Rickman DW (2003) Engraftment of adult neural progenitor cells transplanted to rat retina injured by transient ischemia. Invest Ophthalmol Vis Sci 44:3194-3201

Heins N, Malatesta P, Cecconi F, Nakafuku M, Tucker KL, Hack MA, Chapouton P, Barde YA, Gotz M (2002) Glial cells generate neurons: the role of the transcription factor Pax6. Nat Neurosci 5:308-315

Hicks D, Courtois Y (1992) Fibroblast growth factor stimulates photoreceptor differentiation in vitro. J Neurosci 12:2022-2033

Hunter DD, Murphy MD, Olsson CV, Brunken WJ (1992) S-laminin expression in adult and developing retinae: a potential cue for photoreceptor morphogenesis. Neuron 8:399-413

Jadhav AP, Cho SH, Cepko CL (2006) Notch activity permits retinal cells to progress through multiple progenitor states and acquire a stem cell property. Proc Natl Acad Sci USA 103:18998-19003

James J, Das AV, Bhattacharya S, Chacko DM, Zhao X, Ahmad I (2003) In vitro generation of early-born neurons from late retinal progenitors. J Neurosci 23:8193-8203

Kelley MW, Turner JK, Reh TA (1994) Retinoic acid promotes differentiation of photoreceptors in vitro. Development 120:2091-2102

Kelley MW, Turner JK, Reh TA (1995) Regulation of proliferation and photoreceptor differentiation in fetal human retinal cell cultures. Invest Ophthalmol Vis Sci 36:1280-1289 
Kelley MW, Williams RC, Turner JK, Creech-Kraft JM, Reh TA (1999) Retinoic acid promotes rod photoreceptor differentiation in rat retina in vivo. Neuroreport 10:2389-2394

Khanna H, Akimoto M, Siffroi-Fernandez S, Friedman JS, Hicks D, Swaroop A (2006) Retinoic acid regulates the expression of photoreceptor transcription factor NRL. J Biol Chem 281:27327-27334

Kirsch M, Schulz-Key S, Wiese A, Fuhrmann S, Hofmann H (1998) Ciliary neurotrophic factor blocks rod photoreceptor differentiation from postmitotic precursor cells in vitro. Cell Tissue Res 291:207-216

Klassen HJ, Ng TF, Kurimoto Y, Kirov I, Shatos M, Coffey P, Young MJ (2004) Multipotent retinal progenitors express developmental markers, differentiate into retinal neurons, and preserve lightmediated behavior. Invest Ophthalmol Vis Sci 45:4167-4173

Klassen H, Kiilgaard JF, Zahir T, Ziaeian B, Kirov I, Scherfig E, Warfvinge K, Young MJ (2007) Progenitor cells from the porcine neural retina express photoreceptor markers after transplantation to the subretinal space of allorecipients. Stem Cells 25:1222-1230

Kubo F, Takeichi M, Nakagawa S (2003) Wnt2b controls retinal cell differentiation at the ciliary marginal zone. Development 130:587-598

Kubota A, Nishida K, Nakashima K, Tano Y (2006) Conversion of mammalian Muller glial cells into a neuronal lineage by in vitro aggregate-culture. Biochem Biophys Res Commun 351:514-520

Lamba DA, Karl MO, Ware CB, Reh TA (2006) Efficient generation of retinal progenitor cells from human embryonic stem cells. Proc Natl Acad Sci USA 103:12769-12774

Lavik EB, Klassen H, Warfvinge K, Langer R, Young MJ (2005) Fabrication of degradable polymer scaffolds to direct the integration and differentiation of retinal progenitors. Biomaterials 26:3187-3196

Lendahl U, Zimmerman LB, McKay RD (1990) CNS stem cells express a new class of intermediate filament protein. Cell 60:585-595

Lillien L, Cepko C (1992) Control of proliferation in the retina: temporal changes in responsiveness to FGF and TGF alpha. Development 115:253-266

MacLaren RE, Pearson RA, MacNeil A, Douglas RH, Salt TE, Akimoto M, Swaroop A, Sowden JC, Ali RR (2006) Retinal repair by transplantation of photoreceptor precursors. Nature 444:203-207

Marquardt T, Ashery-Padan R, Andrejewski N, Scardigli R, Guillemot F, Gruss P (2001) Pax6 is required for the multipotent state of retinal progenitor cells. Cell 105:43-55

Mayer EJ, Hughes EH, Carter DA, Dick AD (2003) Nestin positive cells in adult human retina and in epiretinal membranes. Br J Ophthalmol 87:1154-1158

Merhi-Soussi F, Angenieux B, Canola K, Kostic C, Tekaya M, Hornfeld D, Arsenijevic Y (2006) High yield of cells committed to the photoreceptor fate from expanded mouse retinal stem cells. Stem Cells 24:2060-2070

Molofsky AV, Pardal R, Iwashita T, Park IK, Clarke MF, Morrison SJ (2003) Bmi-1 dependence distinguishes neural stem cell selfrenewal from progenitor proliferation. Nature 425:962-967

Moshiri A, Reh TA (2004) Persistent progenitors at the retinal margin of ptc $+/-$ mice. J Neurosci 24:229-237

Nelson BR, Gumuscu B, Hartman BH, Reh TA (2006) Notch activity is downregulated just prior to retinal ganglion cell differentiation. Dev Neurosci 28:128-141

Nelson BR, Hartman BH, Georgi SA, Lan MS, Reh TA (2007) Transient inactivation of Notch signaling synchronizes differentiation of neural progenitor cells. Dev Biol 304:479-498

Neophytou C, Vernallis AB, Smith A, Raff MC (1997) Muller-cell-derived leukaemia inhibitory factor arrests rod photoreceptor differentiation at a postmitotic pre-rod stage of development. Development 124: $2345-2354$
Nishida A, Takahashi M, Tanihara H, Nakano I, Takahashi JB, Mizoguchi A, Ide C, Honda Y (2000) Incorporation and differentiation of hippocampus-derived neural stem cells transplanted in injured adult rat retina. Invest Ophthalmol Vis Sci 41:4268-4274

Ooto S, Akagi T, Kageyama R, Akita J, Mandai M, Honda Y, Takahashi M (2004) Potential for neural regeneration after neurotoxic injury in the adult mammalian retina. Proc Natl Acad Sci USA 101:13654-13659

Osakada F, Ooto S, Akagi T, Mandai M, Akaike A, Takahashi M (2007) Wnt signaling promotes regeneration in the retina of adult mammals. J Neurosci 27:4210-4219

Otani A, Dorrell MI, Kinder K, Moreno SK, Nusinowitz S, Banin E, Heckenlively J, Friedlander M (2004) Rescue of retinal degeneration by intravitreally injected adult bone marrow-derived lineage-negative hematopoietic stem cells. J Clin Invest 114:765-774

Otteson DC, Hitchcock PF (2003) Stem cells in the teleost retina: persistent neurogenesis and injury-induced regeneration. Vision Res 43:927-936

Perron M, Harris WA (2000) Retinal stem cells in vertebrates. Bioessays 22:685-688

Perron M, Kanekar S, Vetter ML, Harris WA (1998) The genetic sequence of retinal development in the ciliary margin of the Xenopus eye. Dev Biol 199:185-200

Qiu G, Seiler MJ, Arai S, Aramant RB, Sadda SR (2004) Alternative culture conditions for isolation and expansion of retinal progenitor cells. Curr Eye Res 28:327-336

Qiu G, Seiler MJ, Mui C, Arai S, Aramant RB, Juan E de Jr, Sadda S (2005) Photoreceptor differentiation and integration of retinal progenitor cells transplanted into transgenic rats. Exp Eye Res $80: 515-525$

Radtke ND, Aramant RB, Seiler MJ, Petry HM, Pidwell D (2004) Vision change after sheet transplant of fetal retina with retinal pigment epithelium to a patient with retinitis pigmentosa. Arch Ophthalmol 122:1159-1165

Rapaport DH, Patheal SL, Harris WA (2001) Cellular competence plays a role in photoreceptor differentiation in the developing Xenopus retina. J Neurobiol 49:129-141

Rapaport DH, Wong LL, Wood ED, Yasumura D, LaVail MM (2004) Timing and topography of cell genesis in the rat retina. J Comp Neurol 474:304-324

Reh TA, Kljavin IJ (1989) Age of differentiation determines rat retinal germinal cell phenotype: induction of differentiation by dissociation. J Neurosci 9:4179-4189

Riobo NA, Manning DR (2007) Pathways of signal transduction employed by vertebrate Hedgehogs. Biochem J 403:369-379

Roger J, Brajeul V, Thomasseau S, Hienola A, Sahel JA, Guillonneau $\mathrm{X}$, Goureau O (2006) Involvement of pleiotrophin in CNTFmediated differentiation of the late retinal progenitor cells. Dev Biol 298:527-539

Rubio D, Garcia-Castro J, Martin MC, de la FR, Cigudosa JC, Lloyd AC, Bernad A (2005) Spontaneous human adult stem cell transformation. Cancer Res 65:3035-3039

Sagdullaev BT, Aramant RB, Seiler MJ, Woch G, McCall MA (2003) Retinal transplantation-induced recovery of retinotectal visual function in a rodent model of retinitis pigmentosa. Invest Ophthalmol Vis Sci 44:1686-1695

Sarmento LM, Huang H, Limon A, Gordon W, Fernandes J, Tavares MJ, Miele L, Cardoso AA, Classon M, Carlesso N (2005) Notch1 modulates timing of G1-S progression by inducing SKP2 transcription and p27 Kip1 degradation. J Exp Med 202:157-168

Saxena MT, Schroeter EH, Mumm JS, Kopan R (2001) Murine notch homologs (N1-4) undergo presenilin-dependent proteolysis. J Biol Chem 276:40268-40273 
Schraermeyer U, Thumann G, Luther T, Kociok N, Armhold S, Kruttwig K, Andressen C, Addicks K, Bartz-Schmidt KU (2001) Subretinally transplanted embryonic stem cells rescue photoreceptor cells from degeneration in the RCS rats. Cell Transplant 10:673-680

Schulz-Key S, Hofmann HD, Beisenherz-Huss C, Barbisch C, Kirsch M (2002) Ciliary neurotrophic factor as a transient negative regulator of rod development in rat retina. Invest Ophthalmol Vis Sci 43:3099-3108

Shiras A, Chettiar S, Shepal V, Rajendran G, Prasad R, Shastry P (2007) Spontaneous transformation of human adult nontumorigenic stem cells to cancer stem cells is driven by genomic instability in a human model of glioblastoma. Stem Cells (in press)

Silva AO, Ercole CE, McLoon SC (2003) Regulation of ganglion cell production by Notch signaling during retinal development. J Neurobiol 54:511-524

Silverman MS, Hughes SE (1989) Transplantation of photoreceptors to light-damaged retina. Invest Ophthalmol Vis Sci 30:1684-1690

Spence JR, Aycinena JC, Rio-Tsonis K (2007) Fibroblast growth factor-hedgehog interdependence during retina regeneration. Dev Dyn 236:1161-1174

Taranova OV, Magness ST, Fagan BM, Wu Y, Surzenko N, Hutton SR, Pevny LH (2006) SOX2 is a dose-dependent regulator of retinal neural progenitor competence. Genes Dev 20:1187-1202

Tomita M, Adachi Y, Yamada H, Takahashi K, Kiuchi K, Oyaizu H, Ikebukuro K, Kaneda H, Matsumura M, Ikehara S (2002) Bone marrow-derived stem cells can differentiate into retinal cells in injured rat retina. Stem Cells 20:279-283

Tomita M, Lavik E, Klassen H, Zahir T, Langer R, Young MJ (2005) Biodegradable polymer composite grafts promote the survival and differentiation of retinal progenitor cells. Stem Cells 23:1579-1588

Tomita M, Mori T, Maruyama K, Zahir T, Ward M, Umezawa A, Young MJ (2006) A comparison of neural differentiation and retinal transplantation with bone marrow-derived cells and retinal progenitor cells. Stem Cells 24:2270-2278

Tropepe V, Coles BL, Chiasson BJ, Horsford DJ, Elia AJ, McInnes RR, Kooy D van der (2000) Retinal stem cells in the adult mammalian eye. Science 287:2032-2036

Turner DL, Snyder EY, Cepko CL (1990) Lineage-independent determination of cell type in the embryonic mouse retina. Neuron 4:833-845

Watanabe T, Raff MC (1990) Rod photoreceptor development in vitro: intrinsic properties of proliferating neuroepithelial cells change as development proceeds in the rat retina. Neuron 4:461-467
Wetts R, Fraser SE (1988) Multipotent precursors can give rise to all major cell types of the frog retina. Science 239:1142-1145

Wetts R, Serbedzija GN, Fraser SE (1989) Cell lineage analysis reveals multipotent precursors in the ciliary margin of the frog retina. Dev Biol 136:254-263

Wojciechowski AB, Englund U, Lundberg C, Warfvinge K (2004) Survival and long distance migration of brain-derived precursor cells transplanted to adult rat retina. Stem Cells 22:27-38

Wu P, Tarasenko YI, Gu Y, Huang LY, Coggeshall RE, Yu Y (2002) Region-specific generation of cholinergic neurons from fetal human neural stem cells grafted in adult rat. Nat Neurosci $5: 1271-1278$

Xu S, Sunderland ME, Coles BL, Kam A, Holowacz T, Ashery-Padan R, Marquardt T, McInnes RR, Kooy D van der (2007) The proliferation and expansion of retinal stem cells require functional Pax6. Dev Biol 304:713-721

Yang J, Klassen H, Pries M, Wang W, Nissen MH (2006) Aqueous humor enhances the proliferation of rat retinal precursor cells in culture, and this effect is partially reproduced by ascorbic acid. Stem Cells 24:2766-2775

Yang P, Seiler MJ, Aramant RB, Whittemore SR (2002) In vitro isolation and expansion of human retinal progenitor cells. Exp Neurol 177:326-331

Yang XJ (2004) Roles of cell-extrinsic growth factors in vertebrate eye pattern formation and retinogenesis. Semin Cell Dev Biol 15:91-103

Yaron O, Farhy C, Marquardt T, Applebury M, Ashery-Padan R (2006) Notch1 functions to suppress cone-photoreceptor fate specification in the developing mouse retina. Development 133:1367-1378

Young MJ, Ray J, Whiteley SJ, Klassen H, Gage FH (2000) Neuronal differentiation and morphological integration of hippocampal progenitor cells transplanted to the retina of immature and mature dystrophic rats. Mol Cell Neurosci 16:197-205

Young RW (1985) Cell differentiation in the retina of the mouse. Anat Rec 212:199-205

Zahir T, Klassen H, Young MJ (2005) Effects of ciliary neurotrophic factor on differentiation of late retinal progenitor cells. Stem Cells 23:424-432

Zahir T, Klassen H, Tomita M, Young MJ (2006) Sorbitol causes preferential selection of Muller glial precursors from late retinal progenitor cells in vitro. Mol Vis 12:1606-1614

Zencak D, Lingbeek M, Kostic C, Tekaya M, Tanger E, Hornfeld D, Jaquet M, Munier FL, Schorderet DF, Lohuizen M van, Arsenijevic Y (2005) Bmil loss produces an increase in astroglial cells and a decrease in neural stem cell population and proliferation. J Neurosci 25:5774-5783 